\title{
Multicentric Study of 148 New Cases of Female Genital Fistula Niger
}

\author{
N. Idi ${ }^{*}$, N. A. Harouna Malam Brah1, A. Idrissa², L. Djangnikpo², Z. Assoumana ${ }^{3}$ \\ ${ }^{1}$ Faculte des Sciences de la Sante, Universite A Moumouni, Niamey, Niger \\ ${ }^{2}$ Centre National de Référence pour la Fistule Obstétricale (CNRFO), Niamey, Niger \\ ${ }^{3}$ UNFPA, Niamey, Niger \\ Email: *idinafi@yahoo.fr
}

How to cite this paper: Idi, N., Brah, N.A.H.M., Idrissa, A. Djangnikpo, L. and Assoumana, Z. (2018) Multicentric Study of 148 New Cases of Female Genital Fistula Niger. Open Journal of Obstetrics and Gynecology, 8, 1631-1639.

https://doi.org/10.4236/ojog.2018.814162

Received: November 16, 2018

Accepted: December 26, 2018

Published: December 29, 2018

Copyright (c) 2018 by authors and Scientific Research Publishing Inc. This work is licensed under the Creative Commons Attribution International License (CC BY 4.0).

http://creativecommons.org/licenses/by/4.0/

\begin{abstract}
Introduction: Obstetric fistula is a public health problem but its prevalence remains unknown in Niger. We report epidemiological and anatomopathological status of new cases of female genital fistula. Method: Multicentre prospective study over 15 months (January $1^{\text {st }}, 2016$ to March $31^{\text {st }}, 2017$ ) in 5 national centers for the therapeutic management of female genital fistula. Data were collected from focus groups, observations and pre-established individual survey form and hospital records. Results: During the 15-month survey period, 148 new cases of female genital fistula of obstetric origin were recorded. Patients aged 15 to 19 accounted for $40 \%$ of cases. They were married before the age of 16 (55.4\%), out of school in $89.2 \%$ and $77.2 \%$ lived outside the matrimonial home. The patients came from rural areas (96\%) of the cases, the labor of delivery lasted more than 24 hours in $71.6 \%$ and in 95.3\% of the cases the delivery was initiated at home and then finished in a health facility, 33.8\% had assisted vaginal delivery (forceps/suction cup), 23\% by caesarean section and $10.81 \%$ by laparotomy for uterine rupture. Fistula occurred during first delivery $(47.3 \%)$ and recurrence accounted for $5.4 \%$ of cases. Perinatal death accounted for $85.1 \%$. Conclusion: Female genital fistula of obstetric origin remains a major public health problem in Niger despite the efforts made.
\end{abstract}

\section{Keywords}

Feminine Genital Fistula, Niger

\section{Introduction}

The female genital fistula represents a major public health problem, with a very negative impact in the area of reproductive health. 
This is the case of countries in sub-Saharan Africa, South Asia and some Arab States [1].

The World Health Organization estimates that 2,000,000 women live with obstetric fistula worldwide with 50,000 to 100,000 new cases each year, or 100 cases per day [2] [3].

To respond to the global campaign to eliminate the TF launched by the United Nations Fund for Population (UNFPA) in 2003, Niger has created a national network for fistula elimination (réseau d'éradication de fistule, REF), with the aim of contributing to improving the health status of the population [4].

Objective is to contribute to a better knowledge of this disease, by looking at the epidemiological, anatomical of female genital fistula of obstetric origin.

\section{Methodology and Patients}

This is a prospective multicenter descriptive study that has been used to collect patients in 5 centers for the treatment of female genital fistula (CNRFO) in Niamey National Reference Center for Obstetric Fistula (CNRFO), Dosso regional centers, Tahoua, Zinder and the Danja fistula center (Maradi region). from January 1, 2016 to March 31, 2017 for a period of 15 months.

They were included in our study all cases of female genital fistula of obstetric origin registered in the relevant departments during the study period and were not included cases of fistula occurring outside the period selected for the study or patients cases of female genital fistula of non-obstetrical cause.

Data were collected from focus groups (after informed and accepted consent), observations, pre-established individual survey form, any observed ethical rule.

\section{Results}

1) General appearance

During our study, 148 cases of female genital fistula of obstetric origin were recorded in treatment centers.

2) Epidemiological aspects

The average age of the patients was 24 years old with extremes 15 and 46 years. All age years old groups of women were affected. The 15 - 19 years old age group was the most exposed with $40 \%$ of cases (Table 1, Table 2). Patients aged 15 - 19 years old, were more numerous in the Tahoua and Maradi regions with 15 and 12 cases, respectively. All major ethnic groups in the country were concerned, Haoussa (52\%), Zerma (21\%), Touareg (16.2\%) and Fulani (7.4\%), respecting the proportions of the country's ethnic groups (Figure 1). Niamey was the most represented with 42 cases $(28.4 \%)$, followed by that of Zinder 32 cases $(21.6 \%)$. The patients were from rural areas $96 \%$ and $89.2 \%$ and out-of-school $97.97 \%$ and 117 . The patients hight (79\%) were upper $150 \mathrm{~cm}$ and 76 patients (51.4\%) had a weight over $50 \mathrm{Kg}$. The primiparous represented $40 \%$ and the multiparas $39.9 \%$ (Table 3 ).

All patients were married, had any occupation $95 \%$, and in $84.5 \%$ of cases, 
Table 1. Patents by years old at 1rst marriage.

\begin{tabular}{ccc}
\hline Age (years old) & $\mathrm{N}$ & $\%$ \\
\hline 12 ans & 4 & 2.70 \\
13 ans & 10 & 6.75 \\
14 ans & 29 & 19.60 \\
15 ans & 39 & 26.35 \\
16 ans & 21 & 14.18 \\
17 ans & 21 & 14.18 \\
18 ans & 8 & 5.40 \\
19 ans & 11 & 7.43 \\
20 ans & 4 & 2.70 \\
23 ans & 1 & 0.67 \\
Total & 148 & 100 \\
\hline
\end{tabular}

Table 2. Patients years old at 1st delivery.

\begin{tabular}{ccc}
\hline Age (years old) & N & $\%$ \\
\hline 15 ans & 37 & 25 \\
16 ans & 29 & 19.60 \\
17 ans & 27 & 18.24 \\
18 ans & 23 & 15.54 \\
19 ans & 6 & 4 \\
20 ans & 13 & 8.78 \\
21 ans & 6 & 4 \\
22 ans & 5 & 3.37 \\
23 ans & 1 & 0.67 \\
25 ans & 1 & 0.67 \\
Total & 148 & 100 \\
\hline
\end{tabular}

\section{$52.00 \%$}

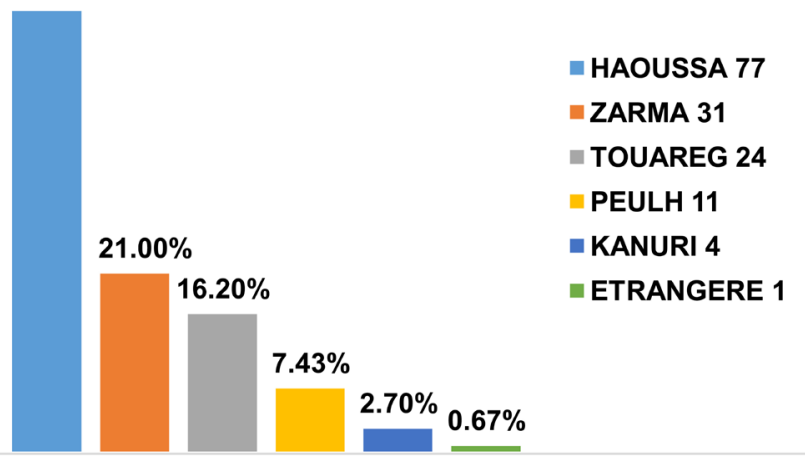

Figure 1. Patients by ethnic group. 
Table 3. Patients by parity.

\begin{tabular}{ccc}
\hline Parity & N & $\%$ \\
\hline I & 70 & 47,32 \\
$2-3$ & 19 & 12,83 \\
$4-5$ & 24 & 16,21 \\
$>5$ & 35 & 23,64 \\
Total & 148 & 100 \\
\hline
\end{tabular}

husbands were farmers or ranchers. Only one case of divorce was noted.

3) Monitoring pregnancy and childbirth

Prenatal follow-up was $58.10 \%$ with at least 3 prenatal visits. In 106 patients (71.6\%), delivery labor had lasted more than 48 hours. They delivered by caesarean section $(33.8 \%)$, or laparotomy for uterine rupture $(33.8 \%)$ and assisted vaginal delivery (forceps, vacum extractor) 48 cases or $32.4 \%$. All patients had given birth only one child, for a total of 148 newborns, $85.14 \%$ of them were stillborn.

4) Clinical aspects

Urogenital fistula was the most common (94.6\%) with only one fistula diagnosed in $96.6 \%$. Vesico-vaginal fistula was the most common type of anatomy found in 66 cases (47.2\%) followed by urethro-vaginal fistula 36 cases (25.7\%), and Recto-Vaginal Fistula (RVF) cases were recorded. therefore 2 cases (66.7\%) sit at the lower $1 / 3$ of the rectum and 1 case $(33.3 \%)$ at the top $1 / 3$ of the rectum.

5 cases of association of urogenital fistula (FUG) and FRV were recorded: the same anatomical type of urogenital fistula was found in 3 cases namely, the urethrovaginal fistula associated respectively with cases of FRV upper third of the rectum a in the middle third of the rectum and one lower third case of the rectum, a juxta-cervical fistula associated with a rectovaginal fistula of the upper third of the rectum, a vesico-vaginal fistula associated with a rectovaginal fistula of the upper third of the rectum.

Fistula was associated with vaginal fibrosis in $8.8 \%$ of patients. $46.6 \%$ fistulas deemed simple by surgeons. 44 patients (29.7\%) had complex fistulas and 35 patients (23.6\%) had fistulas of intermediate complexity.

\section{Discussions and Comments}

1) Epidemiological aspects

a) Age

All age groups of women of childbearing age were affected, with a prevalence of the 15 to 19 age group (40\%). $82.5 \%$ of the patients of this survey were between 15 and 35 years old as in some studies in 2005 in Niger [1], 2011 in Nantes [4], Sanda [5] in Niger in 2001, who found respectively an average age of $26.42,24$, and 26 years old. 


\section{b) Age at first mariage}

The average age at first marriage of the patients was 15.6 years old, with extremes of 12 and 20 years, $89.16 \%$ of them were married before the age of 19 years old, $55.40 \%$ before the age of 16 years old. Patients married before the age of 16 in the regions of Zinder and Tahoua with respectively $28.2 \%$ and $24.4 \%$.

In this study, $92.68 \%$ of patients whose age of less than 16 years old at first marriage had any scolarship. Non-enrollment exposed to early marriage, non-completion of prenatal consultations; too ignorant of the risks of no skilled home delivery assistance or in decision-making to go ton a health facility for delivery. The out-of-school population (not early marriage) would therefore be a population with high-risk pregnancy with complicated delivery. These remarks were made Nafiou [1] in Niger in 2005 and Mariko [6] in 2006 in Mali, Ouattara $\mathrm{K}$ [7] in 2010 in Mali.

c) Ethnic group

The main ethnic groups of Niger were concerned, more than half inHaoussa (52\%), zerma (21\%). The frequency of FGF respected the proportion of different ethnic groups in the country.

d) Marital status

This study reports that $97.97 \%$ of the patients were married, one divorce case. Only $20.7 \%$ lived with their husbands so married status does not guarantee the couple's life; indeed $77.24 \%$ of the married patients lived at their parents home as $89.47 \%$ reported by Hadiza [8] in 2012 in Niger, however lower rates are noted by Nafiou. [1] in 2005 in Niger, Mariko [6] in 2006 in Mali and Djadda [9] in 2006 in Senegal respectively: 52\%, 73.5\% and $75 \%$.

e) Women's level of education and socio-economic status

Since education is an indirect reflection of occupation and socio-economic status, most FGFs occur in poor women living in settings where women's status and self-esteem depend almost entirely on their ability to work. marriage or their ability to have children; whereas the direct causes of fistula are dystocia and lack of emergency skilled obstetric care; extrem poverty is an important underlying cause. Women with FGF are poor, malnourished, lack basic education and live in very remote rural areas [8]-[14].

f) Area of life

The patients came from rural 96\%. Such a distribution is in perfect accordance with the data of the literature. In fact, rural women, far from health centers without means of emergency medical evacuation, with less access to obstetric care, are more generally exposed to the obstetrical complications of dystocia, particularly fistula [15].

2) Rank of the causal childbirth

In this series, $47.3 \%$ of our patients had fistula after the first delivery. The regions of Tahoua and Maradi predominated with respectively a rate of $27.14 \%$ and $21.42 \%$ of primipares as in that of Nafiou. [1] in Niger in 2005, Dekou [3] in 1999 in Côte d'Ivoire, and Wall [15] in Nigeria in 2004 with respectively 43\%, $44.29 \%$ and $45 \%$ of primiparous patients. Multiparas are also involved with 
$39.85 \%$ of cases, against Sanda [5] in Niger in 2001 and Ouattara [9] in Mali in 2010 , which found respectively $21 \%$ and $21.4 \%$ of cases of large multiparous.

If primiparous and large multiparous are exposed to fistula and incontinence, the causes are different. For primiparous women it is generally due to the resistance of the uterus myoma, which is rarely broken, but for large multiparas, the cause is generally dynamic with uterus and the pelvic floor having been too often used get tired. and there is often a cessation of childbirth with often rupture of the uterus lesion of neighboring organs.

Women do not have access to care, because of ignorance, the existence of alternative solutions (traditional practices?), the unfavorable status of women, inadequate health facilities and awareness.

3) Place of delivery

We noted $95.28 \%$ of patients had delivered in a health facility, of which $29.05 \%$ in a maternity hospital. However, $4.05 \%$ had delivered at home and $0.67 \%$ while on the move.

Our results are superior to those reported by Nafiou [1] in Niger in 2005, Hillary [16] in 2004 in Kenya and Diakite [17] in 2008 in Mali, which found respectively $59.5 \%, 79 \%$ and $87.5 \%$ of cases. Unlike our findings other authors had noted rates home delivery fairly high. Sanda [5] in Niger reported that about $64.8 \%$ of fistula patients had delivered at home.

The low relative rate of home birth in our series (4.05\%) can be explained by the fact that most of our patients during delivery had started their delivery work at home and when the dystocia with the impossibility of giving birth, the patients were directed to a health center where the delivery had finally ended. In fact delivery was practiced in the health structures by instrumental extraction, caesarean or uterine rupture cure In this study, $31.03 \%$ of patients had given birth in a the first health facility level and all had a delivery time between $24 \mathrm{~h}$ to 48 h (Table 4).

Childbirth in Niger rural areas is traditionally provided by a matron. The matron capacity for management is sometimes a delay factor in the evacuation of patients to the skilled health centers. The economic vulnerability of the population is another barrier to access to the health center.Fistula can occur in a maternity ward if patients are not admitted on time or when they have not received skilled obstetric care they need, or because the provision of basic obstetric care is non-existent, that is, for various reasons, due to lack of access to local health services. The long delay in accessing emergency obstetric care is a risk factor.

3) Clinical aspects

a) Anatomic type of fistula (Table 5 \& Table 6)

The study revealed that $47.15 \%$ of urogenital fistulas were vesico-vaginal and $25.71 \%$ urethro-vaginal, 3 cases of rectovaginal fistula had been recorded, including 2 cases in the lower third of the rectum and one case in the upper third. 
Table 4. Duration of delivery.

\begin{tabular}{ccc}
\hline Duration of delivery & $\mathrm{N}$ & $\%$ \\
\hline$<12 \mathrm{H}$ & 1 & 0.67 \\
$12-24 \mathrm{H}$ & 41 & 27.70 \\
$24-48 \mathrm{H}$ & 87 & 58.80 \\
$\geq 72 \mathrm{H}$ & 19 & 12.83 \\
Total & 148 & 100 \\
\hline
\end{tabular}

Table 5. Anatomo patholigical findings by years old goup.

\begin{tabular}{cccccccc}
\hline Age(years old) & $15-19$ & $20-24$ & $25-29$ & $30-34$ & $35-39$ & $\geq 40$ & Total \\
\hline Type of FGF & 1 & 1 & 0 & 1 & 0 & 0 & 3 \\
recto-vaginal & 56 & 26 & 18 & 14 & 19 & 7 & 140 \\
uro-genital & 1 & 1 & 1 & 1 & 1 & 0 & 5 \\
Mixte & 58 & 28 & 19 & 16 & 20 & 7 & 148 \\
Total & & & & &
\end{tabular}

Table 6. FGF by Region.

\begin{tabular}{ccc}
\hline Country/region & $\mathrm{N}$ & $\%$ \\
\hline Diffa & 5 & 3.38 \\
Dosso & 22 & 14.86 \\
Maradi & 30 & 20.28 \\
Niamey & 4 & 2.70 \\
Sokoto (Nigeria) & 1 & 0.67 \\
Tahoua & 32 & 21.63 \\
Tillabéry & 28 & 18.91 \\
Zinder & 26 & 17.57 \\
Total & 148 & 100
\end{tabular}

The association of a rectovaginal fistula and a urogenital fistula was found in (five) 5 patients including 3 cases the same anatomical type recto-vaginal fistula of the upper third of the rectum, one of the middle third of the rectum and one of the lower third of the rectum. For the two other cases, there was a rectovaginal fistula of the upper third of the rectum associating respectively a juxta-cervical fistula and a vesico-vaginal fistula.

Our results are comparable to those of Nafiou. [1] in Niger in 2005 who found in 53.2\% of cases fistulas were vesico-vaginal siege, and those of Daouda [18] in Mali in 2013 which reported 5 cases of association of uro-genital fistula and rectal fistula -vaginale.

b) Vaginal fibrosis:

In our study, vaginal flexibility was noted in $91.22 \%$ of cases against $8.78 \%$ of 
vaginal fibrosis. This rate is higher than those reported by Berthe $\mathrm{H}$ [19] and Mariko [6] who found respectively $50 \%$ and $57.8 \%$ of flexible vagina. Vaginal flexibility is a prerequisite for the success of the operative procedure.

\section{Conclusion}

Female genital fistula of obstetric origin remains a major public health problem in Niger. This study reveals that it occurs in very young women, primiparous as well as multiparous, generally poor, very often illiterate, with limited access to health services, especially to reproductive health care.

\section{Conflicts of Interest}

The authors declare no conflicts of interest regarding the publication of this paper.

\section{References}

[1] Nafiou, I., Idrissa, A., Ghaichatou, A.K., Roenneburg, M.L., Wheeless, C.R. and Genadry, R.R. (2007) Obstetric Vesico-Vaginal Fistulas at the National Hospital of Niamey, Niger. International Journal of Gynecology and Obstetrics, 99, 571-574. https://doi.org/10.1016/j.ijgo.2007.06.012

[2] Anoukoum, T., Attipou, K.K., Agoda-Koussema, L.K., AKpadaza, K. and Ayite, E.A. (2010) Aspects épidémiologiques, étiologiques et thérapeutique de la fistule obstétricale au Togo. Progrès en urologie. Elsevier Masson, 20, 71-76.

[3] Konan, P.G., Fofana, A., Kramo, N.F., Vodi, C.C., Gowe, E.E., Dekou, A.H., Ouegnin, G.A., Manzan, K. and Nigue, L. (2015) Les fistules urogénitales (FUG) dans le service d'urologie du CHU de cocody. Aspects évolutifs de 1990 à 2010. Progrès en Urologie, 25, 474-481.

[4] Xavier, D. Fistules obstétricales au Burundi. Résultats de 173 patientes opérées dans le cadre de missions chirurgicales de Gynécologie Sans Frontières entre 2007 et 2010. Mémoire DES Gynécologie Obstétrique, Nantes 2011, 58 pages.

[5] Sanda, G., Nafiou, I. and Mounkaila, A. (2001) La fistule urogénitale au Niger, Aspects épidémiologiques et conséquences. African Journal of Urology, 7, 103-108.

[6] Mariko, S. Les fistules urogénitales, Expérience du service d'urologie de l'hôpital du point $\mathrm{G}$ à propos de 72 cas. Thèse de Médecine $\mathrm{N}^{\circ} 4$, Bamako 2000, 48 pages.

[7] Ouattara, K. Problématique de la FVV obstétricale, service d'urologie, Hôpital du point G. Bamako Mali, [consultée le 05/07/2017]. Disponible sur internet: http://www.gfmer.org/

[8] Nana Hadiza, T. Fistule obstétricale, Aspects épidémiologique, clinique et thérapeutique à la Maternité issaka Gazobi à propos de 57 cas. Mémoire DES gynécologie Obstétrique, Niamey 2012, 91 pages.

[9] Djadda, A. Les pesanteurs socioculturelles et comportementales des fistules obstétricales. Memoire de Maitrise, 2006, 42-47.

[10] Tahzib, F. (1983) Epidemiologicaldeterminants of vésico vaginal fistulas. BJOG: $A n$ International Journal of Obstetrics \& Gynaecology, 90, 387-391. https://doi.org/10.1111/j.1471-0528.1983.tb08933.x

[11] Adama, T.O. (2003) Etude des fistules urogénitales au CHUSS de Bobo-Dioulasso: Aspects épidémiologiques, anatomiques et thérapeutiques, à propos de 57 cas opérés en deux ans. Thèse en Médecine, Burkina Faso, 124 p. 
[12] Falandry, L., lllo, A., Durasnel, P., Alphonsi, R. and Madougou, M. (1997) Urethroplastie labiale pédiculée: Un procédé original de traitement des lésions urethrales étendues d'origine obstétricale. Médecine Tropicale, 57, 273-279.

[13] Harouna, Y.D., Seibou, A., Maikano, S., Djambeidou, J., Sangaré, A., Bilane, S., et al. (2001) La fistule vésico-vaginale de cause obstétricale: Enquête auprès de 52 femmes admises au village des fistuleuses. Médecine d Afrique Noire, 48, 55-59.

[14] Gueye, S.M., Ba, M., Sylla, C., Diagne, B.A. and Mensah, A. (1992) Les fistules vésico-vaginales: Aspects épidémiologiques et thérapeutiques au Sénégal. Journal d Urologie, 98, 148-151.

[15] Wall, L.L., Karshima, J.A., Kirschner, C. and Arrowswith, S.D. (2004) The Obstetric Vesicovaginal Fistula: Characteristics of 899 Patients from Jos, Nigeria. American Journal of Obstetrics and Gynecology, 190, 1011-1019.

https://doi.org/10.1016/j.ajog.2004.02.007

[16] Hillary, M. (2004) Characteristics of Women Admitted with Obstetric Fistula in the Rural Hospitals in West Pokot, Kenya. Post Graduate Training Course in Reproductive Health. http://www.gfmer.org

[17] Diakité, M. (2008) Etude des aspects gynécologiques des fistules vésico-vaginales obstétricales au service d'urologie du CHU point $\mathrm{G}$. Thèse de médecine Bamako No. 225.

[18] Daouda, S. (2013) Etude des facteurs influençant les résultats dans la prise en charge de fistule Uro-génitale. Thèse de Médecine Mali, 66.

[19] Berthe, H. (1999) L'étude des fistules uro-génitales dans le service d'urologie de l'hôpital NianankoroFomba de Ségou à propos de 16 cas Thèse de Médecine No. 61 . Bamako, 85 p. 